\title{
Metal-Organic Conjugated Microporous Polymer Containing a Carbon Dioxide Reduction Electrocatalyst
}

\author{
Charlotte L. Smith, ${ }^{\mathrm{a}, \mathrm{b}}$ Rob Clowes, ${ }^{\mathrm{a}}$ Reiner Sebastian Sprick, ${ }^{a}$ Andrew I. Cooper, ${ }^{\mathrm{a}}$ and \\ Alexander J. Cowan ${ }^{a, b^{*}}$
}

\begin{abstract}
A metal-organic conjugated micorporous polymer (CMP) containing a manganese carbonyl electrocatalyst for $\mathrm{CO}_{2}$ reduction has been synthesised and electrochemically characterised. Incorporation in a rigid framework changes the behavior of the catalyst, preventing reductive dimerization. These initial studies demonstrate the feasibility of CMP electrodes that can provide both high local $\mathrm{CO}_{2}$ concentrations and well defined electrocatalytic sites.
\end{abstract}

The capture and electrocatalytic conversion of $\mathrm{CO}_{2}$ into useful feedstocks and fuels is one of the most pressing challenges facing the chemistry community. ${ }^{1}$ Historically electrocatalytic $\mathrm{CO}_{2}$ reduction has been addressed via two main routes. Careful design has delivered molecular electrocatalysts with extremely high turnover frequencies, and in many cases low onset potentials, for $\mathrm{C} 1$ products such as $\mathrm{CO}$ and $\mathrm{HCOOH}^{2-4}$ However, the majority of studies involve catalysts that are only soluble in organic solvents, an environment that also provides high $\mathrm{CO}_{2}$ concentrations and supresses the undesired hydrogen evolution reaction. In contrast, heterogeneous electrodes ${ }^{5}$ including metals such as $\mathrm{Cu}, \mathrm{Au}$ and $\mathrm{Ag}$ have shown high current densities and stability in water, but rational design of the catalyst centre is challenging. Recently, a number of studies have demonstrated a third route using crystalline porous materials. High levels of activity for electrocatalytic $\mathrm{CO}_{2}$ reduction have been reported for covalent organic frameworks (COFs) ${ }^{6,7}$ and metal organic frameworks $(\mathrm{MOFs})^{8-10}$ that contain molecular electrocatalysts within the framework. Such an approach has significant advantages as it provides electrode materials with welldefined tuneable, catalytic in a stable heterogenised form. A range of porous organic polymers that lack long-range order are also known. ${ }^{11}$ Amongst these are CMPs, materials formed by the polymerisation of rigid strut units with a high degree of $\pi$-conjugation across the network. ${ }^{12}$ CMPs have excellent thermal stabilities and interesting electrical and photophysical properties. Furthermore,

\footnotetext{
a Department of Chemistry and Materials Innovation Factory, University of Liverpool, Crown Street, Liverpool L69 7ZD, U.K.

b. Stephenson Institute for Renewable Energy, University of Liverpool, Peach Street, Liverpool, U.K.

Electronic Supplementary Information (ESI) available: [Experimental details, PXRD, UV-vis spectra, electrocatalysis studies and control experiments of $\left[\mathrm{Mn}(\mathrm{bpy})(\mathrm{CO})_{3} \mathrm{Br}\right]$ without the CMP framework].
}

many CMPs contain functionalities including porphyrins and bipyridines that can yield metal-organic CMPs through post-polymerization metalation. ${ }^{13} \mathrm{CMPs}$ and metal-organic CMPs have been studied for a wide range of applications $^{14,15}$ including catalysis, electrochemical energy storage and $\mathrm{CO}_{2}$ capture. 16,17 The high concentration of $\mathrm{CO}_{2}$ achievable within the structure is potentially advantageous for $\mathrm{CO}_{2}$ fixation ${ }^{17}$ and this has been exploited with materials for thermal catalysis including $\mathrm{CO}_{2}$ hydrogenation ${ }^{18}$ and cycloaddition to epoxide. ${ }^{19} \quad$ Metal-organic CMPs containing $\left[\mathrm{Re}\right.$ (diimine) $\left.(\mathrm{CO})_{3} \mathrm{Cl}\right]$ moieties have also been used as photocatalysts for $\mathrm{CO}_{2}$ reduction. ${ }^{20}$
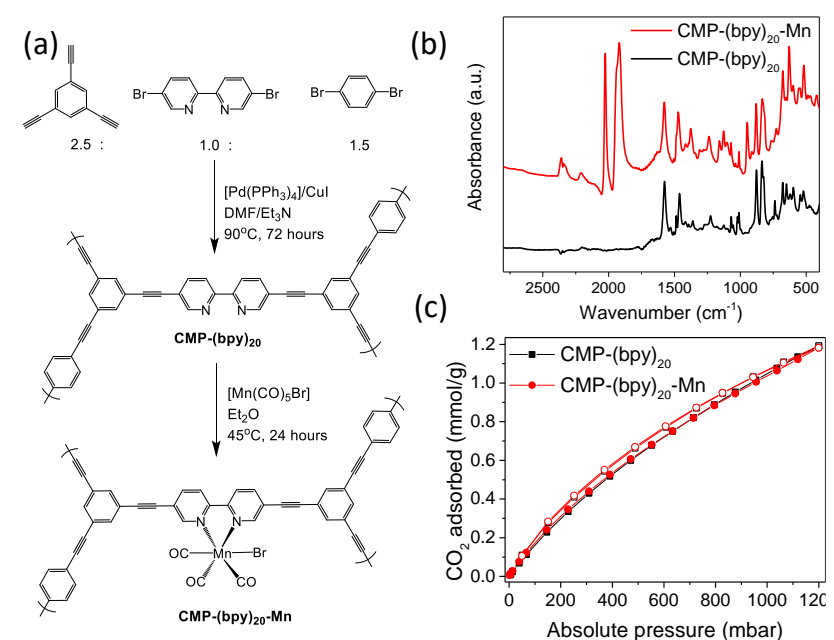
Figure 1. (a) Synthetic route to CMP-(bpy) $20-M n$. The notation for the bpy
content of the polymer arises from the feed percentage of 5,5 -dibromo-2, bipyridine in the polymerisation reaction. (b) FTIR spectra and (c) CO adsorption-desorption isotherms measured at $298 \mathrm{~K}$ for CMP-(bpy) 20 (black) and CMP-(bpy) $20-\mathrm{Mn}$ (red).

One past study examined metal nanoparticle electrodes deposited onto a CMP membrane for $\mathrm{CO}_{2}$ conversion ${ }^{21}$ but metal-organic CMPs with well-defined catalytic centres have not previously been explored as electrode materials for $\mathrm{CO}_{2}$ reduction to the best of our knowledge. Such an approach has a number of potential benefits. Cobalt CMPs for electrocatalytic $\mathrm{O}_{2}$ reduction ${ }^{22}$ and $\mathrm{H}_{2} \mathrm{O}$ oxidation ${ }^{23,24}$ showed activities and stabilities exceeding the equivalent monomeric catalyst units, likely due to improved mass transport within the porous structure, ${ }^{22}$ prevention of catalyst agglomeration ${ }^{23}$ and the conjugated nature of the structure allowing delocalization of charge between catalytic sites. ${ }^{24}$ Furthermore, the ability of CMPs to 
concentrate $\mathrm{CO}_{2}$ within the structure may provide a pathway with the ability for efficient conversion of dilute $\mathrm{CO}_{2}$ sources.

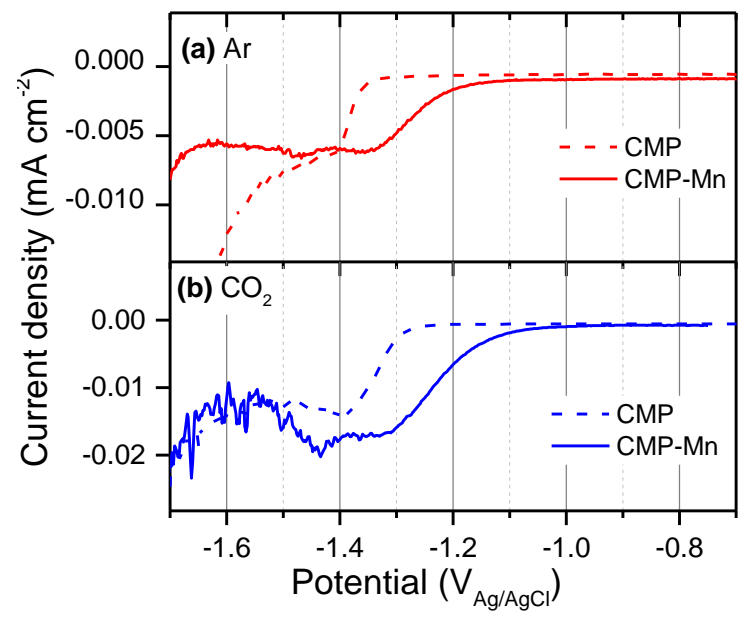

Figure 2. Square wave voltammograms $(\mathrm{a}, \mathrm{b})\left(10 \mathrm{mV} \mathrm{\textrm {s } ^ { - 1 }}\right)$ of CMP-(bpy $)_{20}$ (dashed) and CMP-(bpy) $20-M n$ (solid) in $\mathrm{pH} 7$ phosphate buffer under $\mathrm{Ar}$ (red) ${ }^{\circ} \mathrm{CO}_{2}$ (blue). $\mathrm{CMP}-(\mathrm{bpy})_{20} \mathrm{Mn}$ shows an additional reductio
$-1.35 \mathrm{~V})$ assignable to [Mn(bpy)(CO) ${ }_{3} \mathrm{Br}$ m moieties.

Here we report the electrochemistry of a fac$\left[\mathrm{Mn}(\mathrm{bpy})(\mathrm{CO})_{3} \mathrm{Br}\right]$ moiety incorporated into a CMP framework (the fac- notation is omitted from here on). $\left[\mathrm{Mn}(\mathrm{bpy})(\mathrm{CO})_{3} \mathrm{Br}\right]$ and its derivatives have been shown to be effective electrocatalysts for the reduction of $\mathrm{CO}_{2}$, principally to $\mathrm{CO}^{25,26}$ However, in solution $\left[\mathrm{Mn}(\mathrm{bpy})(\mathrm{CO})_{3} \mathrm{Br}\right]$ undergoes a reduction induced dimerisation prior to formation of the catalytically active species, making its study within the rigid electroactive CMP framework particularly interesting. The synthetic approach reported here is based on that previously reported for a related Re based CMP and a ratio of monomers that was previously identified to give an optimal balance between porosity and density of metal binding sites. ${ }^{13}$ Briefly, the amorphous polymer CMP-(bpy) 20 was prepared by Sonogashira-Hagihara cross-coupling reaction of $1,3,5$ triethynylbenzene with 5,5'-dibromo-2,2'-bipyridine and 1,4-dibromobenzene, Figure 1a, S1. Following purification of CMP-(bpy $)_{20}$ the polymer and $\left[\mathrm{Mn}(\mathrm{CO})_{5} \mathrm{Br}\right]$ are refluxed in $\mathrm{Et}_{2} \mathrm{O}$ for 24 hours yielding a red/brown solid, CMP(bpy) $20-\mathrm{Mn}$.

Inductively coupled plasma-optical emission spectroscopy (ICP-OES) demonstrates inclusion of $5.47 \% \mathrm{Mn}$ by weight within CMP-(bpy) $20-\mathrm{Mn}$. This $\mathrm{Mn}$ loading is close to the calculated maximum (6.41\%) based on $100 \%$ occupancy of all bpy units in the proposed structure in Figure 1. The presence of a tricarbonyl complex is confirmed by FTIR spectroscopy with CMP-(bpy) $20-\mathrm{Mn}$ showing $v(\mathrm{CO})$ bands at 2026, 1940 and $1919 \mathrm{~cm}^{-1}$, and is in-line with the spectra of a similar Mn complex within a photoactive MOF, ${ }^{27}$ Figure 1b. UV/Vis spectroscopy also supports the formation of CMP-(bpy)20-Mn with the presence of a broad absorption from $400-550 \mathrm{~nm}$, that is not seen with CMP-(bpy) 20 , likely due to a MLCT transition, Figure S2. Thermal gravimetric analysis shows a $7 \%$ weight loss for CMP-(bpy)20-Mn, due to the moderate thermal stability of $\left[\mathrm{Mn}(\mathrm{bpy})(\mathrm{CO})_{3} \mathrm{Br}\right]$ $\left(<100^{\circ} \mathrm{C}\right)$, Figure $\mathrm{S} 3 .{ }^{26}$ By contrast, the underlying framework is stable to $>300{ }^{\circ} \mathrm{C}$. We therefore conclude that the $\mathrm{Mn}$ is present as $\left[\mathrm{Mn}(\mathrm{bpycmp})(\mathrm{CO})_{3} \mathrm{Br}\right]$ moieties.

Nitrogen adsorption measurements at $77 \mathrm{~K}$ show that both CMP-(bpy) 20 and CMP-(bpy)20-Mn have a type I and type IV physisorption isotherms with a $\mathrm{H} 2$-hysteresis loop, indicating the presence of mesopores and macropores within the 3D porous network, Figure S4. A slight decrease in surface area (CMP-(bpy) $20=637 \mathrm{~m}^{2} \mathrm{~g}^{-1}$ ) occurs following inclusion of the Mn catalyst (CMP-(bpy) $20-\mathrm{Mn}=549 \mathrm{~m}^{2} \mathrm{~g}$ $\left.{ }^{1}\right)$ and this is also accompanied by a small decrease in pore volume from 0.24 to $0.21 \mathrm{~cm}^{3} \mathrm{~g}^{-1}$. Analysis of the differential pore volume suggests that all materials exhibit a broad range of pores from ultramicroporous $(>1 \mathrm{~nm})$ to macroporous (> $50 \mathrm{~nm}$ ), Figure S5.

The decrease in the specific surface area is mostly due to the increased mass with the Mn present. At $298 \mathrm{~K}$ The CMP-(bpy)20-Mn shows a moderate level of uptake of $\mathrm{CO}_{2}$ $\left(1.06 \mathrm{mmol} \mathrm{g}^{-1}\right)$ at 1 bar. At $273 \mathrm{~K}$ a heat of adsorption of $27 \mathrm{~kJ} \mathrm{~mol}^{-1}$ at low $0.1 \mathrm{mmol} \mathrm{g}^{-1}$, dropping to values $22 \mathrm{~kJ}$ $\mathrm{mol}^{-1} 1 \mathrm{mmol} \mathrm{g}^{-1}$, Figure S6. For reference BPL carbon, a common benchmark material, adsorbs $1.9 \mathrm{mmol} \mathrm{g}^{-1}$ at 298 $\mathrm{K} .{ }^{28}$ As a $\mathrm{CO}_{2}$ capture material per se, CMP-(bpy) ${ }_{20}-\mathrm{Mn}$ is not outstanding, but importantly it remains porous after metallation and able to uptake $\mathrm{CO}_{2}$ within the polymer.
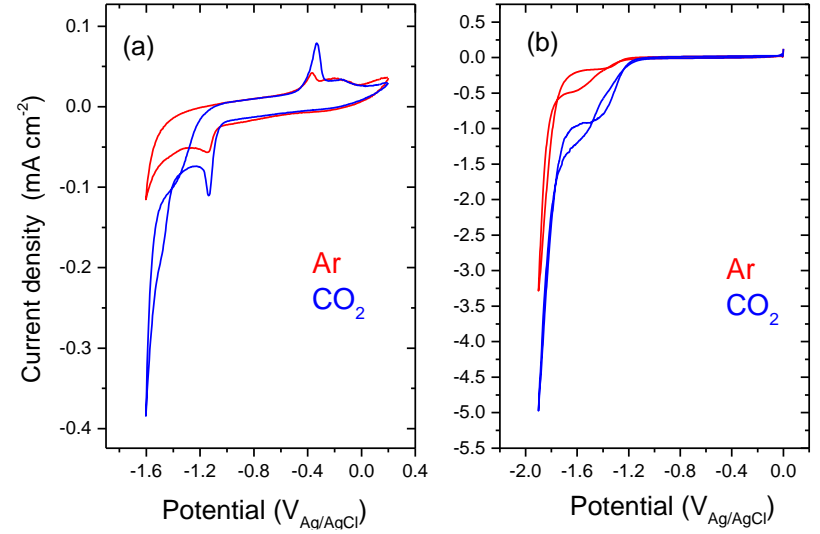

Figure 3. $\mathrm{CVs}$ of (a) $\left[\mathrm{Mn}(\mathrm{bpy})(\mathrm{CO})_{3} \mathrm{Br}\right] / \mathrm{Nafion}$ (b) CMP-(bpy) $)_{20}-\mathrm{Mn} / \mathrm{Nafion}$ both on a glassy carbon electrode in $0.06 \mathrm{M}$ phosphate buffer $\mathrm{pH} 7,10$ $\mathrm{mV} \mathrm{s}-1$ recorded under $\mathrm{CO}_{2}$ and Ar. The data in part (a) is reproduced with permission from reference $\left[{ }^{29}\right]$.

To assess if the Mn centre remains electrochemically active, we carried out experiments in $\mathrm{pH} 7$ aqueous phosphate buffer $(0.06 \mathrm{M})$ under both $\mathrm{CO}_{2}$ and $\mathrm{Ar}$, Figures 2, 3. Electrodes were prepared by deposition of a suspension of either CMP-(bpy) 20 or CMP-(bpy) ${ }_{20}-\mathrm{Mn}$ in an acetonitrile solution containing Nafion ( 0.5 wt. \%) onto a glassy carbon electrode, which was left to dry in air. Square wave voltammetry of CMP-(bpy) 20 shows a single reduction at $-1.46 \mathrm{~V}$ proposed to be due to reduction of the CMP framework, or residual Pd within the sample $(0.24 \pm$ $0.02 \%$ ) that could not be removed, Figure $2 \mathrm{~b}$. CMP- 
(bpy)20-Mn shows the reduction at $-1.46 \mathrm{~V}$, and a new reduction at $-1.35 \mathrm{~V}$ that is assigned to a CMP-Mn based process, Figure $2 \mathrm{~b}$. It is apparent that the catalyst remains electroactive within the CMP framework.

The electrochemical behaviour of $\left[\mathrm{Mn}(\mathrm{bpy})(\mathrm{CO})_{3} \mathrm{Br}\right]$ in organic solution has been studied extensively ${ }^{25,30-33}$ and recently reviewed. ${ }^{34}$ Following initial reduction, bromide
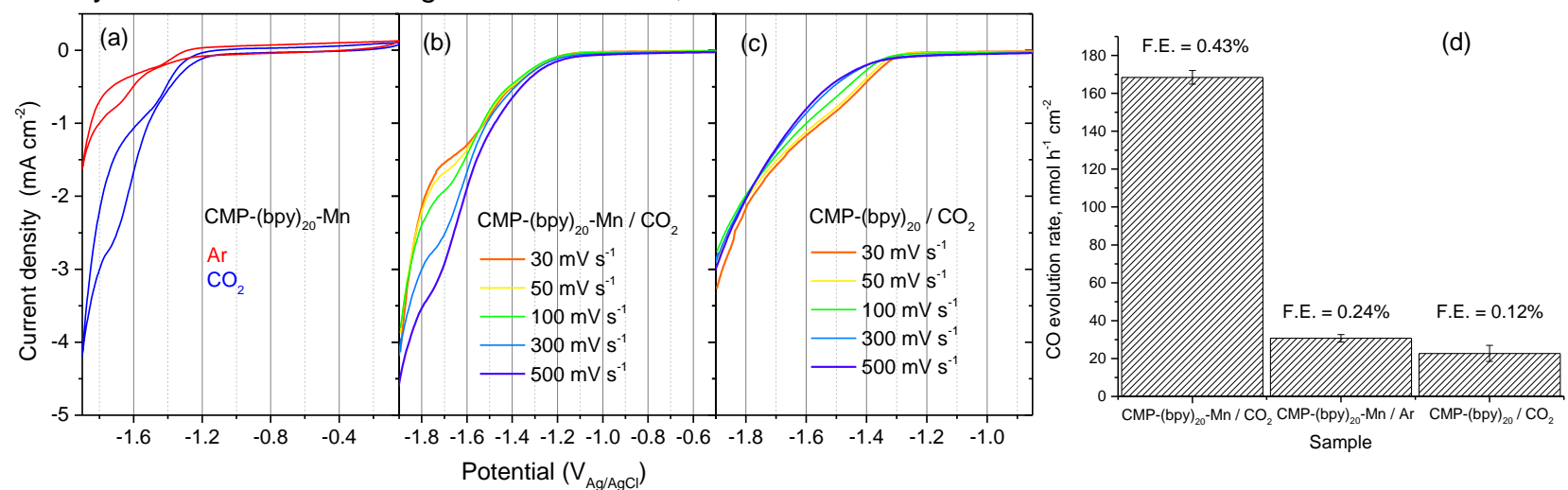

Figure 4. (a) $\mathrm{CV}$ of CMP-(bpy)2o-Mn in pH 7 phosphate buffer under $\mathrm{Ar}$ (red) and $\mathrm{CO}_{2}$ (blue) ( $300 \mathrm{mV} \mathrm{s}^{-1}$ ). Linear sweep scan rate dependence of (b) in the unmodified framework. (d) CO evolution rate during bulk electrolysis experiments at -1.6 $\mathrm{V}_{\mathrm{Ag} / \mathrm{Agcl}}$ for 3 hours. The Faradic efficiencies are for $\mathrm{CO}$. $\mathrm{H}_{2}$ was the only other product detected.

Although $\mathrm{CO}_{2}$ reduction can occur via the dimer complex in solution the turn-over frequency (TOF) is significantly lower. ${ }^{32,35}$ The observation of a single reduction assignable to the Mn site at $-1.35 \mathrm{~V}$ for CMP-(bpy)20-Mn indicates that the incorporation of the catalytic centre within the rigid CMP prevents dimerisation. Previously, [Mn(bpy) $\left.(\mathrm{CO})_{3} \mathrm{Br}\right]$ has been immobilised using a range of methods including; casting the unmodified complex in Nafion, ${ }^{29}$ the noncovalent immobilization of a pyrene modified complex ${ }^{36}$ and by binding of phosphonated and carboxylated derivatives $^{37,38}$ to oxide supports. Remarkably in these past studies dimerisation still occurred due to the use of flexible linkers or formation of catalyst aggregates. Comparison between the previously recorded CVs of $\left[\mathrm{Mn}(\mathrm{bpy})(\mathrm{CO})_{3} \mathrm{Br}\right]$ in Nafion ${ }^{29}$ and CMP-(bpy) ${ }_{20}-\mathrm{Mn}$ (Figure 3) further supports the conclusion that the rigid framework prevents dimerisation. For $\left[\mathrm{Mn}(\mathrm{bpy})(\mathrm{CO})_{3} \mathrm{Br}\right]$ in Nafion, reductions at -1.15 and $-1.47 \mathrm{~V}$ are assignable to $\left[\mathrm{Mn}(\mathrm{bpy})(\mathrm{CO})_{3} \mathrm{Br}\right]$ and $\left[\mathrm{Mn}_{2}(\mathrm{bpy})_{2}(\mathrm{CO})_{6}\right]$ and an oxidation peak at $-0.35 \mathrm{~V}$ is due to the dimer. ${ }^{29}$ In contrast with CMP(bpy) $20-\mathrm{Mn}$ we see no evidence of the dimer oxidation, figure 3(b). The shift in the reduction potential of the $\mathrm{Mn}$ centre in CMP-(bpy)20-Mn (-1.35 V) compared to [Mn(bpy) $\left.(\mathrm{CO})_{3} \mathrm{Br}\right](-1.15 \mathrm{~V})$ is due to to the modification of the bpy ligand and the presence of the Mn centre within the conjugated framework of the CMP. ${ }^{34}$

Dimer formation has been prevented previously in acetonitrile solutions through addition of sterically bulky groups to the bpy ligand.4,39 There, the monomer anion $\left(\left[\mathrm{Mn}(\text { bpy- } \mathrm{R})(\mathrm{CO})_{3}\right]^{-}\right)$was formed by an initial one electron reduction and ligand loss step, followed by a second reduction with a formal potential positive of the first, giving rise to the observation of a single reduction $(-1.55 \mathrm{~V} v s$. loss from the complex occurs, leading to rapid dimerization. Subsequent reduction of $\left[\mathrm{Mn}_{2}(\mathrm{bpy})_{2}(\mathrm{CO})_{6}\right]$, formation of the primary catalytically-active species, $\left[\mathrm{Mn}(\mathrm{bpy})(\mathrm{CO})_{3}\right]^{-}$, which in the presence of a suitable weak Brønsted acid can bind to $\mathrm{CO}_{2}$. typically at potentials a further $0.3 \mathrm{~V}$ negative, leads to the
$\mathrm{Fc} / \mathrm{Fc}^{+}$, ca. $-1.17 \mathrm{~V}$ vs. $\left.\mathrm{Ag} / \mathrm{AgCl}\right)$. Here, we propose that the reduction at $-1.35 \mathrm{~V}$ in Figure $2 \mathrm{a}$ is the two-electron reduction to generate a $\left[\mathrm{Mn}(\mathrm{bpycmP})(\mathrm{CO})_{3}\right]^{-}$moiety within the CMP framework. Past reports in solution using bulky ligands, $\mathrm{CO}_{2}$ binding led to a positive shift in reduction potential and the formation of a $\mathrm{Mn}^{\mathrm{I}}-\mathrm{CO}_{2} \mathrm{H}$ intermediate. ${ }^{39}$ We also find that under $\mathrm{CO}_{2}$, the CMP-Mn based reduction shifts by $30 \mathrm{mV}$ to more positive values, indicating $\mathrm{CO}_{2}$ binding to the reduced $\mathrm{Mn}$ centre within the CMP framework can also occur, Figure $2 b$.

Under $\mathrm{CO}_{2}$ using CMP-(bpy) ${ }_{20}-\mathrm{Mn}$ we observe a small increase (ca. $\times 2.5$ at $-1.35 \mathrm{~V}$, Figure 2a, 3a) in current density between $-1.2 \mathrm{~V}$ and $-1.4 \mathrm{~V}$. Over this potential region, increasing the scan rate of the $C V$ does not lead to a significant increase in current density suggesting that substrate $\left(\mathrm{CO}_{2}, \mathrm{H}^{+}\right)$diffusion is not limiting catalysis, Figure 3b. ${ }^{1}$ By contrast, between -1.6 and $-1.8 \mathrm{~V}$, the plateau current under $\mathrm{CO}_{2}$ increases with scan rate. This indicates the presence of a second higher TOF catalytic pathway that is substrate limited. Interestingly, the current-density for CMP-(bpy) 20 under $\mathrm{CO}_{2}$ does not increase with scan rate between -1.6 and $-1.8 \mathrm{~V}$ demonstrating that the second higher TOF pathway is CMP-Mn based, Figure 3c. The observation of a fast catalytic pathway, $0.25 \mathrm{~V}$ negative of the potential where $\mathrm{CO}_{2}$ binding initially occurs, mirrors that reported when $\mathrm{Mn}$ dimerisation was prevented in solution. ${ }^{39}$ In that study, at potentials positive of the reduction potential of $\mathrm{Mn}-\mathrm{CO}_{2} \mathrm{H}$, catalysis proceeded by a slow pathway, reliant on the rate limiting formation of a $[\mathrm{Mn}$ (bpy) $(\mathrm{CO})] 4^{+}$complex. In contrast, at very negative potentials $\mathrm{Mn}-\mathrm{CO}_{2} \mathrm{H}$ reduction occurred and the fast catalysis pathway dominated. 
The focus of this initial communication is to demonstrate the viability of the approach by showing that the Mn centre remains electrochemically active within the CMP framework. No attempts have been made to optimise the electrode for catalysis. Nonetheless, we have also carried out a preliminary bulk electrolysis study to confirm that the Mn complex remains catalytically active. For CMP-(bpy)20$\mathrm{Mn}$ under $\mathrm{CO}_{2}$ at $-1.6 \mathrm{~V}, \mathrm{CO}$ is the sole carbon-based product formed, Figure S8, 9. Control experiments using CMP-(bpy)20 show a CO evolution rate that is approximately 7 times less than when the Mn catalyst is present and 5 times less under Ar, Figure 3d. This confirms that the Mn centre is acting as the catalytic site (Figure S8) and indicates that $\mathrm{CO}$ is primarily produced from $\mathrm{CO}_{2}$ reduction although isotopic labelling is required to definitively confirm this. The small amount of $\mathrm{CO}$ produced under $\mathrm{Ar}$ may be due to either reduction of $\mathrm{CO}_{2}$ captured from air by the CMP, ligand loss or organic degradation pathways. Unfortunately Faradic efficiencies for $\mathrm{CO}$ are low $(0.43 \%)$ with $\mathrm{H}_{2}$ production dominating. Kubiak et al. have shown ${ }^{4}$ that the presence of $\mathrm{Mg}^{2+}$ can greatly accelerate the "slow catalysis" pathway in solution, allowing for activity at reduced overpotentials which will be explored in future studies as a route to improving the Faradic efficiency for $\mathrm{CO}_{2}$ reduction here also. Furthermore, structural distortions of the CMP framework can lead to a loss of conjugation, leading to insulating regions within the polymer and low electroactive contents (Figure S8) making it likely that gains in electrocatalytic activity can be made by optimising the CMP-supporting electrode interface.

\section{Conclusions}

We report the inclusion and electrochemical behaviour of the well-known $\left[\mathrm{Mn}(\mathrm{bpy})(\mathrm{CO})_{3} \mathrm{Br}\right] \mathrm{CO}_{2}$ reduction catalyst into a CMP framework. This is significant because the CMP is able to act as both a $\mathrm{CO}_{2}$ uptake material and an electroactive support for the Mn catalytic centres. We prevent catalyst dimerization, a target of previous studies, 4,39 because the catalyst is held in a rigid framework. Although Faradic efficiencies are extremely low, CV measurements show the catalytic centre remains active, and this first study represents an important step towards the use of metal-organic CMP materials for the conversion of dilute $\mathrm{CO}_{2}$ sources. Future studies will be focused on the engineering the CMP-(bpy)20-Mn electrode structure, as it is likely that the porous CMP structure can be best exploited through the development of a threephase (gas diffusion) electrodes.

\section{Conflicts of interest}

There are no conflicts to declare

\section{Acknowledgements}

We thank the Engineering and Physical Sciences Research Council (EPSRC) for financial support through EP/K006851/1, EP/P034497/1 and EP/N004884/1.

\section{References}

1 C. Costentin, M. Robert and J.-M. Savéant, Chem. Soc. Rev., 2013, 42, 2423-2436.

2 I. Azcarate, C. Costentin, M. Robert and J.-M. Savéant, J. Am. Chem. Soc., 2016, 138, 16639-16644.

$3 \mathrm{H}$. Takeda, C. Cometto, O. Ishitani and M. Robert, ACS Catal., 2017, 7, 70-88.

4 M. D. Sampson and C. P. Kubiak, J. Am. Chem. Soc., 2016, 138, 1386-1393.

5 B. Khezri, A. C. Fisher and M. Pumera, J. Mater. Chem. A, 2017, 5, 8230-8246.

6 S. Lin, C. S. Diercks, Y.-B. Zhang, N. Kornienko, E. M. Nichols, Y. Zhao, A. R. Paris, D. Kim, P. Yang, O. M. Yaghi and C. J. Chang, Science, 2015, 349, 1208-13.

7 H. Liu, J. Chu, Z. Yin, X. Cai, L. Zhuang and H. Deng, Chem, 2018, 4, 1696-1709.

8 N. Kornienko, Y. Zhao, C. S. Kley, C. Zhu, D. Kim, S. Lin, C. J. Chang, O. M. Yaghi and P. Yang, J. Am. Chem. Soc., 2015, 137, 14129-14135.

9 I. Hod, M. D. Sampson, P. Deria, C. P. Kubiak, O. K. Farha and J. T. Hupp, ACS Catal., 2015, 5, 6302-6309.

10 L. Ye, J. Liu, Y. Gao, C. Gong, M. Addicoat, T. Heine, C. Wöll and L. Sun, J. Mater. Chem. A, 2016, 4, 15320-15326. 11 S. Das, P. Heasman, T. Ben and S. Qiu, Chem. Rev., 2017, 117, 1515-1563.

12 A. I. Cooper, Adv. Mater., 2009, 21, 1291-1295.

13 J.-X. X. Jiang, C. Wang, A. Laybourn, T. Hasell, R. Clowes, Y. Z. Khimyak, J. Xiao, S. J. Higgins, D. J. Adams and A. I. Cooper, Angew. Chemie Int. Ed., 2011, 50, 10721075.

14 M. E. Bhosale, R. Illathvalappil, S. Kurungot and K. Krishnamoorthy, Chem. Commun., 2016, 52, 316-318.

15 Y. Xu, S. Jin, H. Xu, A. Nagai and D. Jiang, Chem. Soc. Rev., 2013, 42, 8012.

16 R. Dawson, E. Stöckel, J. R. Holst, D. J. Adams and A. I. Cooper, Energy Environ. Sci., 2011, 4, 4239.

17 P. Bhanja, A. Modak and A. Bhaumik, ChemCatChem, 2019, 11, 244-257.

18 G. Gunniya Hariyanandam, D. Hyun, P. Natarajan, K.-D. Jung and S. Yoon, Catal. Today, 2016, 265, 52-55.

19 Y. Xie, R.-X. Yang, N.-Y. Huang, H.-J. Luo and W.-Q. Deng, J. Energy Chem., 2014, 23, 22-28.

20 W. Liang, T. L. Church, S. Zheng, C. Zhou, B. S. Haynes and D. M. D'Alessandro, Chem. - A Eur. J., 2015, 21, 18576-18579.

21 C. Ampelli, C. Genovese, M. Errahali, G. Gatti, L. Marchese, S. Perathoner and G. Centi, J. Appl.

Electrochem., 2015, 45, 701-713.

22 G. Lu, H. Yang, Y. Zhu, T. Huggins, Z. J. Ren, Z. Liu and W. Zhang, J. Mater. Chem. A, 2015, 3, 4954-4959.

23 A. Singh, S. Roy, C. Das, D. Samanta and T. K. Maji, Chem. Commun., 2018, 54, 4465-4468.

24 S. Bhunia, K. Bhunia, B. C. Patra, S. K. Das, D. Pradhan, A. Bhaumik, A. Pradhan and S. Bhattacharya, ACS Appl. Mater. Interfaces, 2019, 11, 1520-1528.

25 M. Bourrez, F. Molton, S. Chardon-Noblat and A. Deronzier, Angew. Chem. Int. Ed. Engl., 2011, 50, 99039906.

26 M. Stanbury, J.-D. Compain and S. Chardon-Noblat, Coord. Chem. Rev., 2018, 361, 120-137. 
27 H. Fei, M. D. Sampson, Y. Lee, C. P. Kubiak and S. M. Cohen, Inorg. Chem., 2015, 54, 6821-6828.

28 R. Banerjee, H. Furukawa, D. Britt, C. Knobler, M. O'Keeffe and O. M. Yaghi, J. Am. Chem. Soc., 2009, 131, 3875-3877.

29 J. J. Walsh, G. Neri, C. L. Smith and A. J. Cowan, Chem. Commun., 2014, 50, 12698-12701.

30 B. D. Rossenaar, F. Hartl, D. J. Stufkens, C. Amatore, E. Maisonhaute and J.-N. Verpeaux, Organometallics, 1997, 16, 4675-4685.

31 G. Neri, J. J. Walsh, G. Teobaldi, P. M. Donaldson and A. J. Cowan, Nat. Catal., 2018, 1, 952-959.

32 M. Bourrez, M. Orio, F. Molton, H. Vezin, C. Duboc, A. Deronzier and S. Chardon-Noblat, Angew. Chem. Int. Ed. Engl., 2014, 53, 240-243.

33 J. M. Smieja, M. D. Sampson, K. a Grice, E. E. Benson, J. D. Froehlich and C. P. Kubiak, Inorg. Chem., 2013, 52, 2484-2491.

34 D. C. Grills, M. Z. Ertem, M. McKinnon, K. T. Ngo and J. Rochford, Coord. Chem. Rev., 2018, 374, 173-217.

35 G. Neri, P. M. Donaldson and A. J. Cowan, Phys. Chem. Chem. Phys., 2019, 21, 7389-7397.

36 B. Reuillard, K. H. Ly, T. E. Rosser, M. F. Kuehnel, I. Zebger and E. Reisner, J. Am. Chem. Soc., 2017, 139, 14425-14435.

37 J. J. Walsh, M. Forster, C. L. Smith, G. Neri, R. J. Potter and A. J. Cowan, Phys. Chem. Chem. Phys., 2018, 20, 6811-6816.

38 T. E. Rosser, C. D. Windle and E. Reisner, Angew. Chemie Int. Ed., 2016, 55, 7388-7392.

39 M. D. Sampson, A. D. Nguyen, K. a Grice, C. E. Moore, A. L. Rheingold and C. P. Kubiak, J. Am. Chem. Soc., 2014, 136, 5460-5471. 


\title{
Metal-Organic Conjugated Microporous Polymer Containing A Carbon Dioxide Reduction Electrocatalyst
}

\author{
Charlotte L. Smith, Rob Clowes, Reiner Sebastian Sprick, Andrew I. Cooper, and Alexander
} J. Cowan*

\section{Supporting information}

Materials: Milli-Q water (18.2 M 2 ) was used throughout (Millipore Corp). All chemicals were purchased from Sigma Aldrich except for 5,5'-dibromo-2,2'-bipyridyl which was purchased from TCI Chemicals. 3 mm GCE were purchased from IJ Cambriam Scientific Ltd. Argon and helium N6 grade, and $\mathrm{CO}_{2} \mathrm{CP}$ grade were purchased from BOC. Calibrant gas for the $\mathrm{GC}$ was a custom order of $500 \mathrm{ppm}$ $\mathrm{H}_{2}$ and $200 \mathrm{ppm} \mathrm{CO}$ in helium.

Synthesis of CMP-(bpy $)_{20}$ : Under an argon atmosphere 1,4-dibromobenzene $(0.35 \mathrm{~g}, 0.75 \mathrm{mmol}), 5,5$ dibromo-2,2-bipyridine $(0.34 \mathrm{~g}, 0.50 \mathrm{mmol})$ and 1,3,5-triphenylbenzene $(0.375 \mathrm{~g}, 1.25 \mathrm{mmol})$ were stirred under reflux at $90^{\circ} \mathrm{C}$ for 3 days in DMF $(8 \mathrm{~mL})$ and $\mathrm{NEt}_{3}(8 \mathrm{~mL})$ with $\mathrm{CuI}(20 \mathrm{mg})$ and $\left[\mathrm{Pd}\left(\mathrm{PPh}_{3}\right)_{4}\right](40 \mathrm{mg})$. Over the 3-day period the mixture had turned from a brown suspension to a brown solid. The polymer was then ball milled for 30 minutes, to obtain a powder which was then washed and purified via Soxhlet extraction with methanol at $90{ }^{\circ} \mathrm{C}$ for 3 days. Yield: $322 \mathrm{mg}(81 \%)$. Elemental combustion analysis (\%) calculated for $\mathrm{C}_{24.5} \mathrm{H}_{9.75} \mathrm{~N}$ : C 92.52, H 3.06, N 4.40; Found: C 82.17, H 3.42, $\mathrm{N}$ 4.14. Please note: The elemental composition was calculated ignoring defects within the material, molecular weight distribution and the presence of end-groups whose nature is unclear.

Synthesis of CMP-(bpy) 20 $-\mathbf{M n}$ : CMP-(bpy $)_{20}(0.25 \mathrm{~g}, 0.39 \mathrm{mmol})$ was suspended in diethyl ether with $\left[\mathrm{Mn}(\mathrm{CO})_{5} \mathrm{Br}\right](0.25 \mathrm{~g}, 0.9 \mathrm{mmol})$ and heated to $45^{\circ} \mathrm{C}$ for 24 hours. The obtained red/brown solid was washed with methanol, water and chloroform $(50 \mathrm{~mL}$ each) and a Soxhlet extraction was carried out with DCM at $75{ }^{\circ} \mathrm{C}$. Yield: $300 \mathrm{mg}$, (67\%). Elemental combustion analysis (\%) calculated for $\mathrm{C}_{26} \mathrm{H}_{9.75} \mathrm{NO}_{1.5} \mathrm{Mn}_{0.5} \mathrm{Br}_{0.5}$ : C 73.11, H 2.28, N 3.28; Found: C 61.10, H 3.58, N 2.98. Pd content determined by ICP-OES: $0.24 \pm 0.02 \%$. Mn content determined by ICP-OES: $5.47 \pm 0.21 \%$.

ICP-OES and CHN analysis: Carried out by the University of Liverpool analytical services. ICP-OES samples were prepared via microwave digestion using a PerkinElmer titan. Digestion was carried out in concentrated nitric acid, and the temperature was ramped to $170{ }^{\circ} \mathrm{C}$ over a ramp time of 5 minutes at 30 bar and held for 5 minutes, then increased to $210^{\circ} \mathrm{C}$ over 3 minutes at 30 bar and held for 45 minutes. Finally, the temperature was lowered to $50{ }^{\circ} \mathrm{C}$ over 1 minute at $30 \mathrm{bar}$ and held for 15 minutes. The sample was diluted with water to $14 \%$ nitric acid content before ICP-OES analysis.

Materials characterisation: UV/Vis absorption spectra were recorded on a Shimadzu UV-2550 UVVisNIR spectrometer as powders. Fourier-transform infrared (FTIR) spectra were recorded using a JASCO 4000 FTIR in an ATR geometry (resolution, $4 \mathrm{~cm}^{-1}$ ). Powder x-ray-diffraction (PXRD) measurements were performed on a PANalytical X'Pert PRO MPD, with a Cu X-ray source, used in high throughput transmission mode with $\mathrm{K} \alpha$ focusing mirror and PIXCEL 1D detector. Thermogravimetric analysis (TGA) measurements were performed on an EXSTAR6000 by heating samples at rate of $5{ }^{\circ} \mathrm{C} \mathrm{min}{ }^{-1}$ under an air flow of $25 \mathrm{~mL} \mathrm{~min}^{-1}$ and nitrogen flow of $10 \mathrm{~mL} \mathrm{~min}{ }^{-1}$, in open aluminium pans from 40 to $600{ }^{\circ} \mathrm{C}$ and holding at $600{ }^{\circ} \mathrm{C}$ for 30 minutes.

Gas sorption properties: Surface area and pore size distributions were performed on a Micromeritics ASAP 2020 volumetric adsorption analyzer under nitrogen or $\mathrm{CO}_{2}$ at $77.4 \mathrm{~K}$. Samples were degassed at $120^{\circ} \mathrm{C}$ or $60^{\circ} \mathrm{C}$ for 15 hours under vacuum $\left(10^{-5}\right.$ bar $)$ prior to analysis. 
Electrochemical analysis: Experiments were carried out in a 3-neck flask containing a $\mathrm{Ag} / \mathrm{AgCl}$ reference electrode, Pt counter electrode and glassy carbon working electrode. Working electrodes were prepared by casting $10 \mu \mathrm{L}$ of a sample containing a suspension of either CMP-(bpy) ${ }_{20}$ or CMP-(bpy $)_{20}$ Mn (5.5 mg mL $\left.\mathrm{m}^{-1}\right)$ in a Nafion (at $0.5 \%$ weight) acetonitrile/alcohol solution onto a GCE $\left(0.07 \mathrm{~cm}^{2}\right)$. The Nafion acetonitrile/alcohol solution is prepared by dilution of a $5 \%$ weight Nafion in mixed lower aliphatic alcohol solution (Sigma Aldrich, used as supplied) in acetonitrile. All samples were dried in air. The electrolyte used was either $60 \mathrm{mM}$ buffer. The cell was kept in the dark using aluminium foil for the entire experiment. The cell was purged with argon or $\mathrm{CO}_{2}$ for 20-30 minutes before starting the experiment. Palmsens or emstat potentiostats were used. During bulk electrolysis experiments the $\mathrm{Pt}$ counter electrode was kept being a Vycor tip containing ferrocene carboxylic acid in $0.1 \mathrm{M} \mathrm{KOH}$. The electrolyte was stirred through the experiment. Samples were purged with $\mathrm{CO}_{2}$ and then sealed. $100 \mu \mathrm{L}$ injections were recorded of the cell headspace periodically and analysed using an Agilent $6890 \mathrm{~N}$ with N6 helium as the carrier gas $\left(5 \mathrm{~mL} \mathrm{~min}^{-1}\right)$. A $5 \AA$ molecular sieve column (ValcoPLOT, $30 \mathrm{~m}$ length, $0.53 \mathrm{~mm}$ ID) and a pulsed discharge detector (D-3-I-HP, Valco Vici) were employed. At the end of the experiment the electrolyte was also examined for formate production by ion chromatography using an Eco IC (Metrohm) instrument with a sup 5-150/4 column.
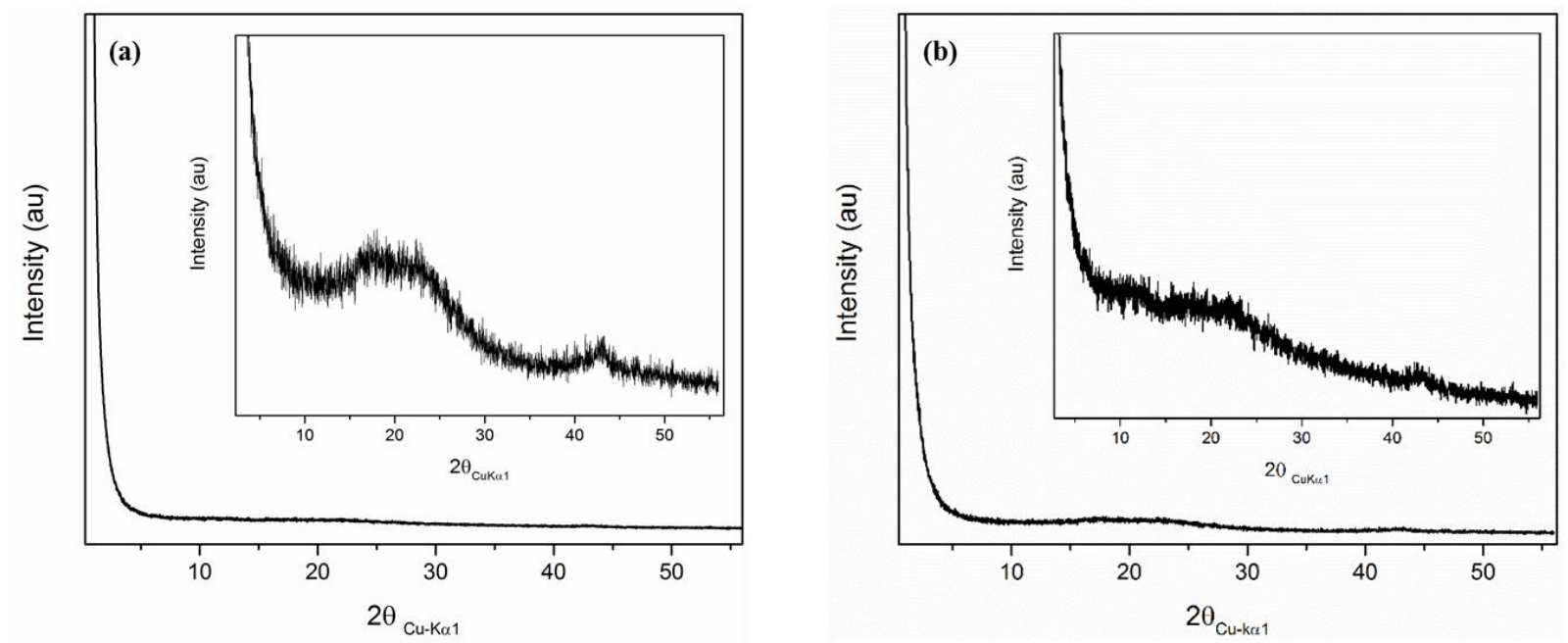

Figure S1: PXRD patterns of a) CMP and b) CMP-bpyMn, both of which can be seen to be amorphous materials. 


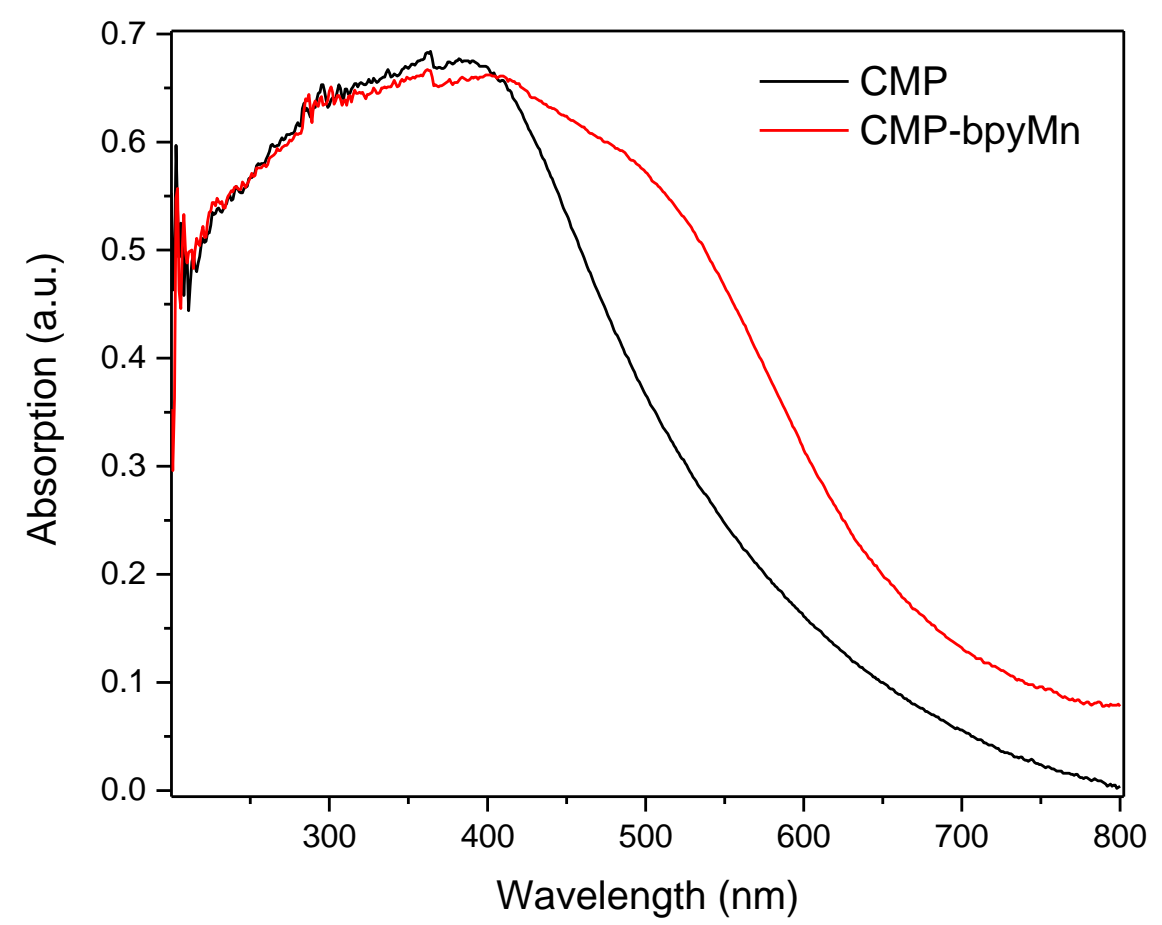

Figure S2. UV/Vis spectra of CMP-(bpy) ${ }_{20}$ (black) and CMP-(bpy) ${ }_{20}-\mathrm{Mn}$ (red).

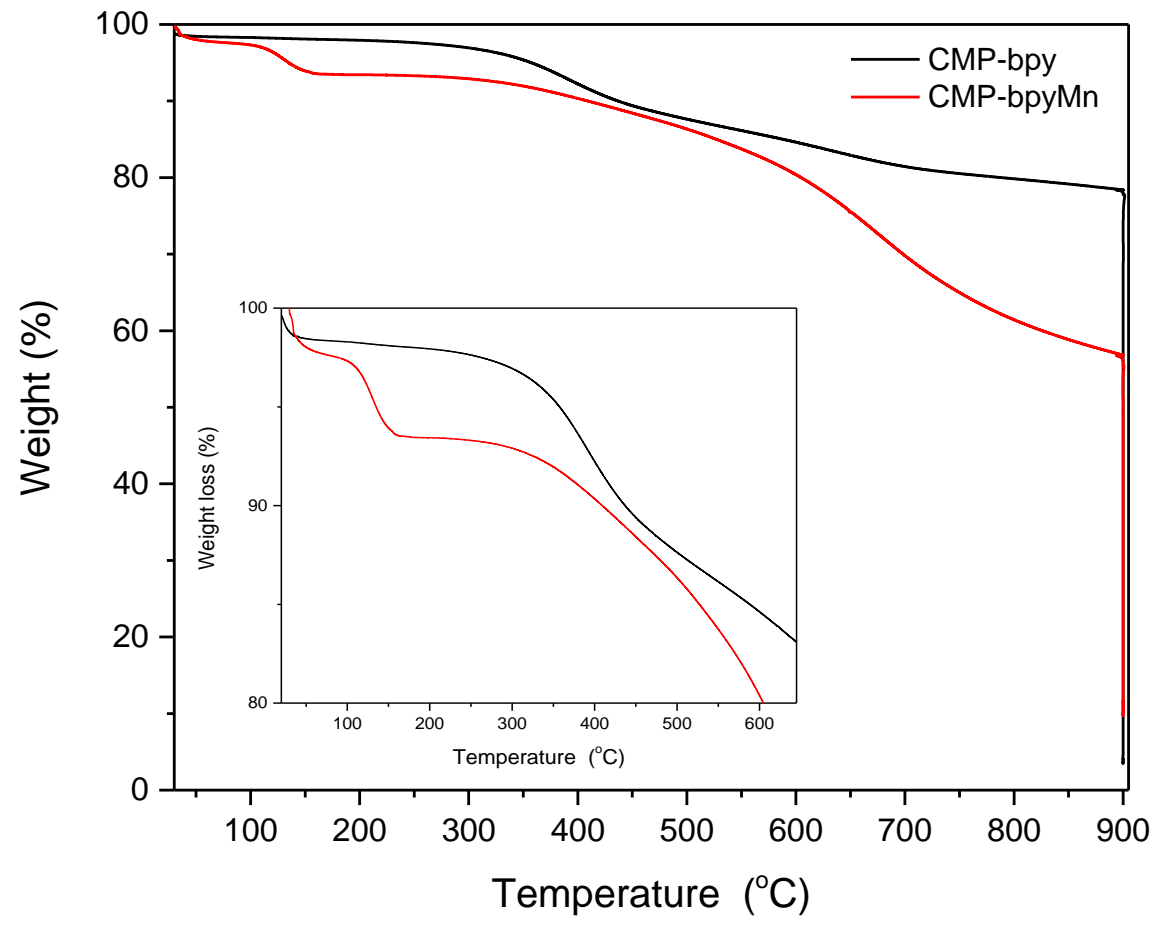

Figure S3. Thermal gravimetric analysis of CMP-(bpy) ${ }_{20}$ (black) and CMP-(bpy) ${ }_{20}-\mathrm{Mn}$ (red) under a nitrogen atmosphere. The inset shows the mass loss at $\sim 150{ }^{\circ} \mathrm{C}$ for $\mathrm{CMP}-(\mathrm{bpy})_{20} \mathrm{-Mn}$ that is not observed with CMP-(bpy) $)_{20}$. 


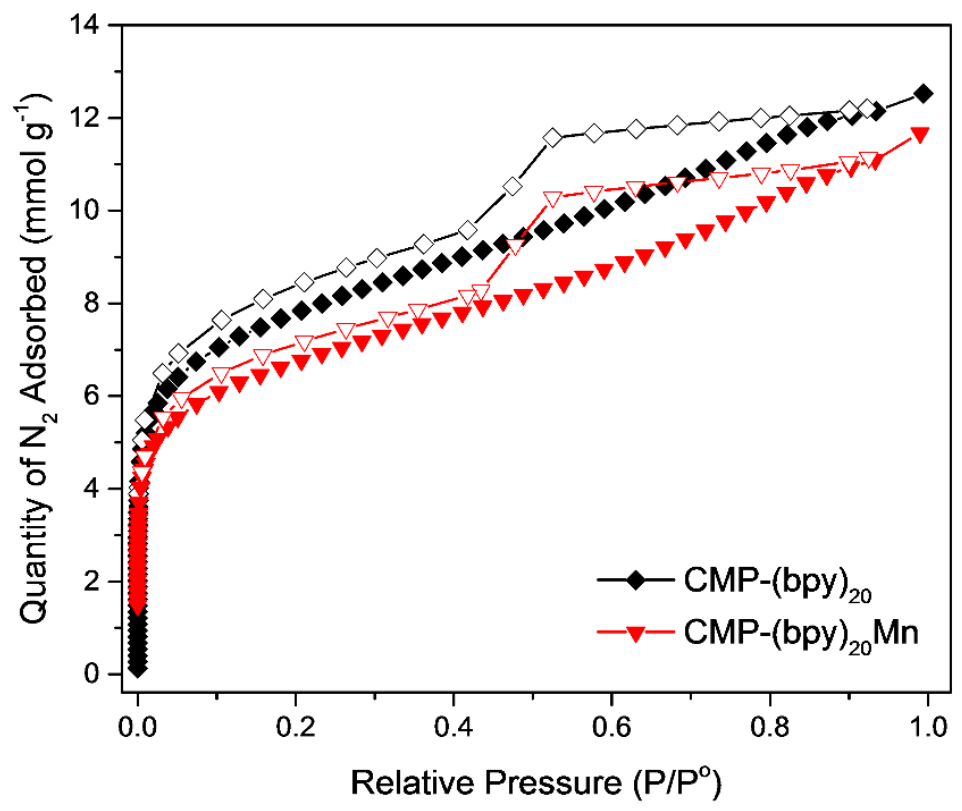

Figure S4. $\mathrm{N}_{2}$ adsorption-desorption isotherms measured at $77.4 \mathrm{~K}$ for CMP-(bpy) ${ }_{20}$ (black) and CMP(bpy) ${ }_{20}-\mathrm{Mn}$ (red).

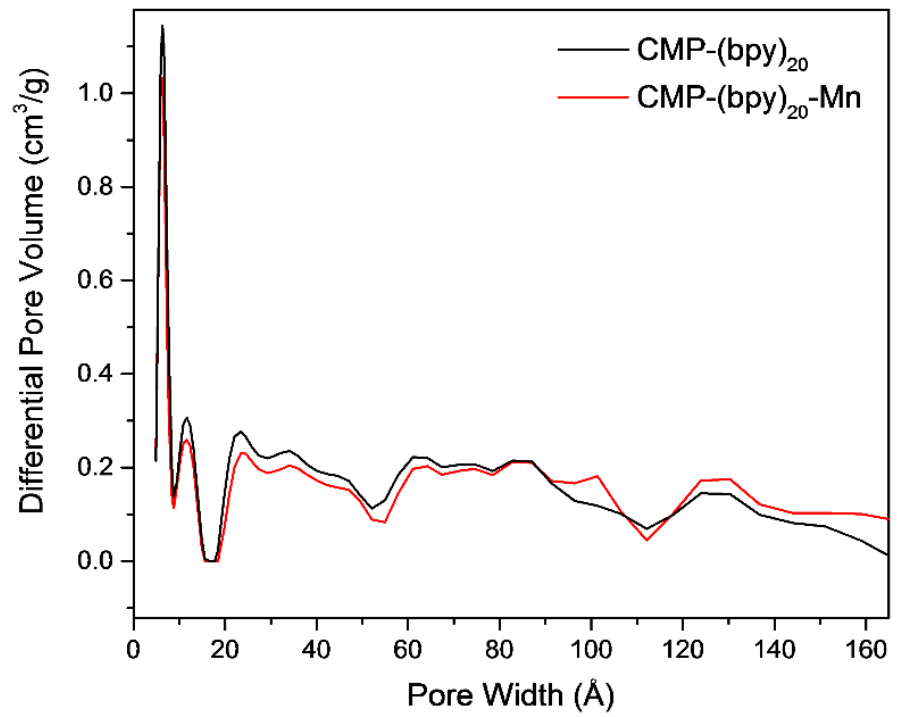

Figure S5. Differential pore volume of CMP-(bpy) ${ }_{20}$ (black) and CMP-(bpy) ${ }_{20}-\mathrm{Mn}$ (red) measured under $\mathrm{N}_{2}(77.4 \mathrm{~K})$ showing the pore distribution is maintained following addition of the Mn centre. 

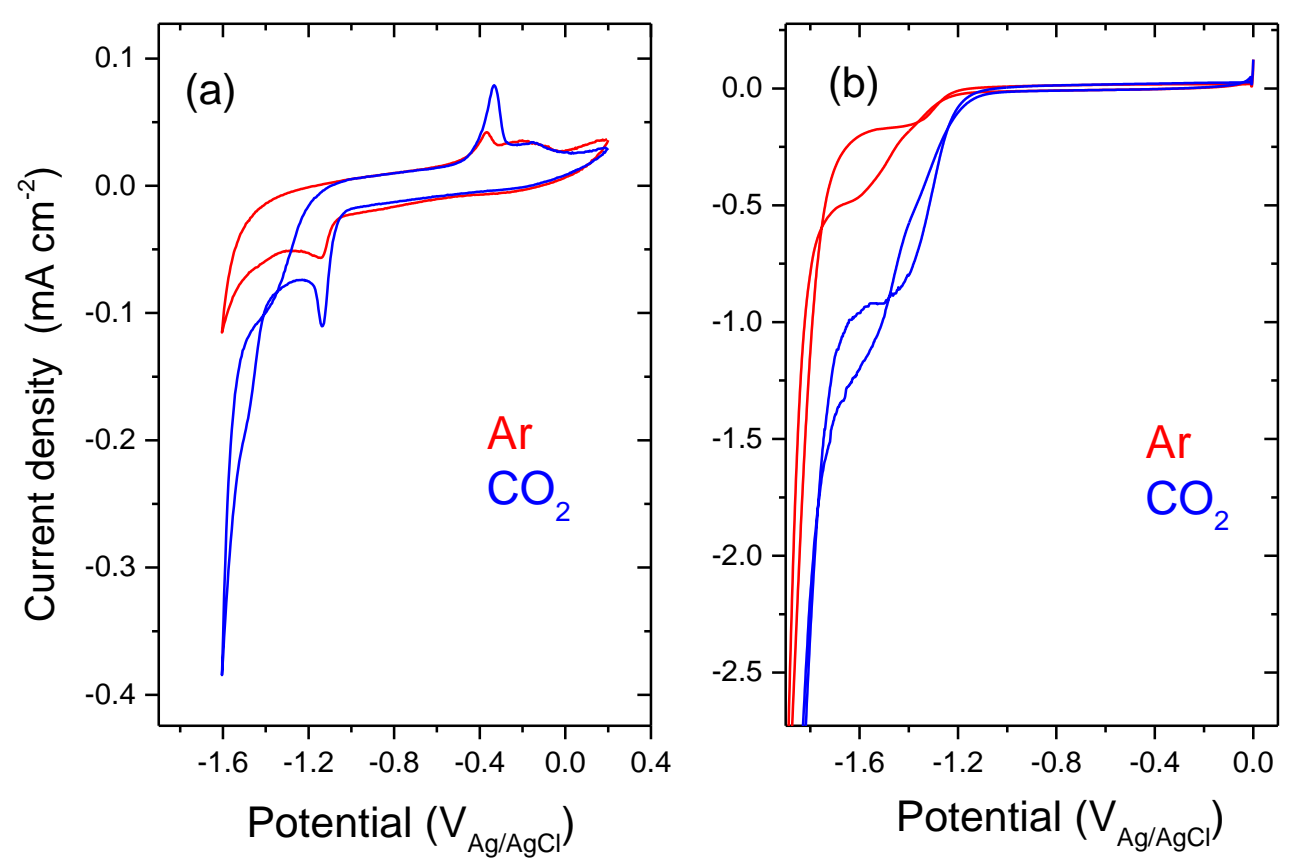

Figure S6. CVs of (a) $\left[\mathrm{Mn}(\mathrm{bpy})(\mathrm{CO})_{3} \mathrm{Br}\right] / \mathrm{Nafion}$, (b) CMP-(bpy) ${ }_{20}-\mathrm{Mn} / \mathrm{Nafion}$, both on a glassy carbon electrode in $0.06 \mathrm{M}$ phosphate buffer $\mathrm{pH} 7,10 \mathrm{mV} \mathrm{s}^{-1}$ recorded under $\mathrm{CO}_{2}$ and Ar. The data in part (a) is replotted from reference $\left.{ }^{1}\right]$. Electrodes are prepared using $10 \mu \mathrm{l}$ of a solution containing of either $\left[\mathrm{Mn}(\mathrm{bpy})(\mathrm{CO})_{3} \mathrm{Br}\right]$ or CMP-(bpy) ${ }_{20}-\mathrm{Mn}$ on a $0.07 \mathrm{~cm}^{2}$ electrode.

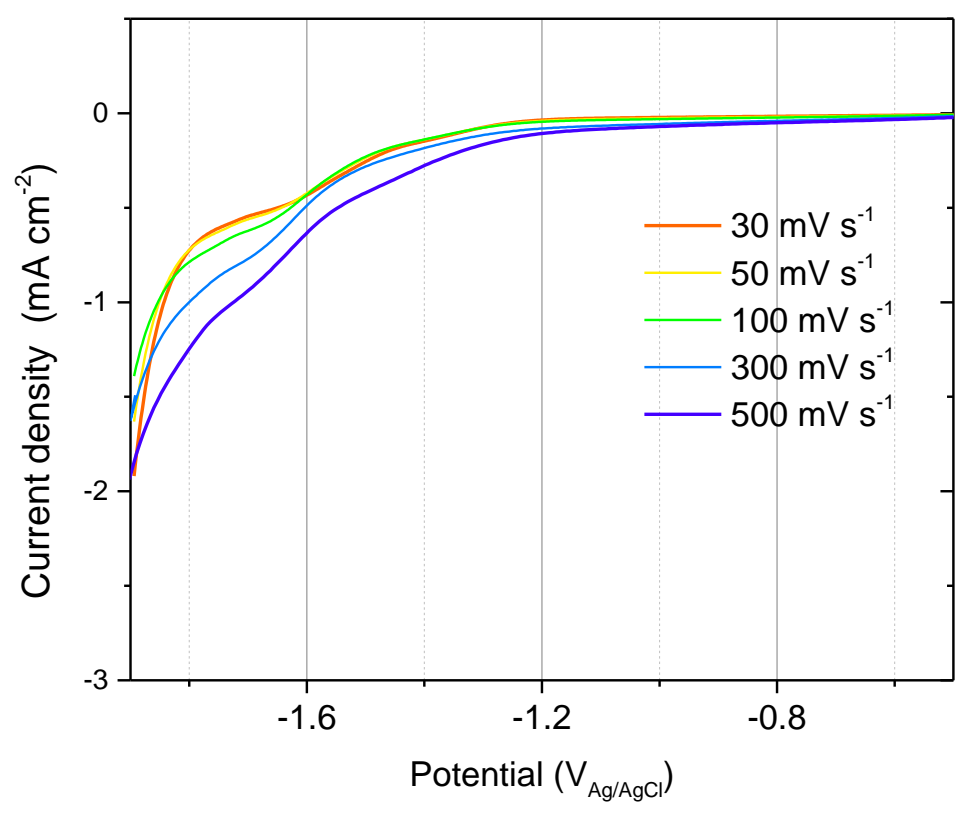

Figure S7. Linear sweep voltammetry of CMP-(bpy) ${ }_{20}-\mathrm{Mn}$ in $0.06 \mathrm{M}$ phosphate buffer $\mathrm{pH} 7$, $10 \mathrm{mV} \mathrm{s}^{-1}$ recorded under Ar atmosphere. 


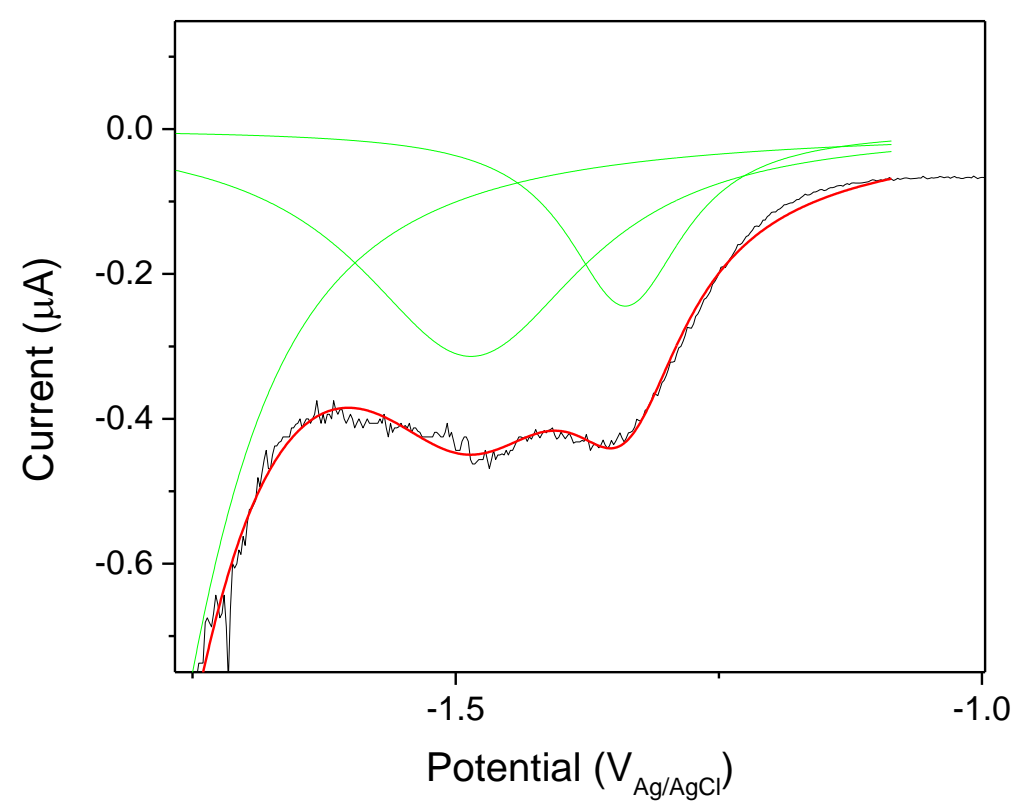

Figure S8. Square wave voltammetry of CMP-(bpy) ${ }_{20}-\mathrm{Mn}$ in $0.06 \mathrm{M}$ phosphate buffer $\mathrm{pH} 7,10 \mathrm{mV} \mathrm{s}$ ${ }^{1}$ recorded under Ar atmosphere. Integration of the reductive feature in the SWV assigned to the Mn centre indicates $5.2 \times 10^{-6} \mathrm{C}$ is passed, corresponding to an estimated $2.7 \times 10^{-11} \mathrm{~mol}$ of electroactive $\mathrm{Mn}$ on a $0.07 \mathrm{~cm}^{2} \mathrm{GCE}$ assuming a two-electron reduction. Using this estimate of the electroactive content it is possible to arrive at an approximate TON over 4 hours of 1296 . However great caution should be taken when interpreting the square-wave voltammograms of polymer thin films quantitatively, ${ }^{2}$ and we highlight this value to be a best estimate. Regardless of the absolute value it is clear that the electroactive content is low. This is likely due to the fact that only the CMP-(bpy) ${ }_{20}-\mathrm{Mn}$ particles in direct contact with the GCE will be active and this represent a small fraction of the overall material deposited. Furthermore structural distortions of the CMP structure can lead to a loss of conjugation which will make regions of each polymer particle insulating.

\section{References:}

[1] J. J. Walsh, G. Neri, C. L. Smith and A. J. Cowan, Chem. Commun., 2014, 50, 12698-12701

[2] V. Mirčeski, R. Gulaboski and F. Scholz, J. Electroanal. Chem., 2004, 566, 351-360. 